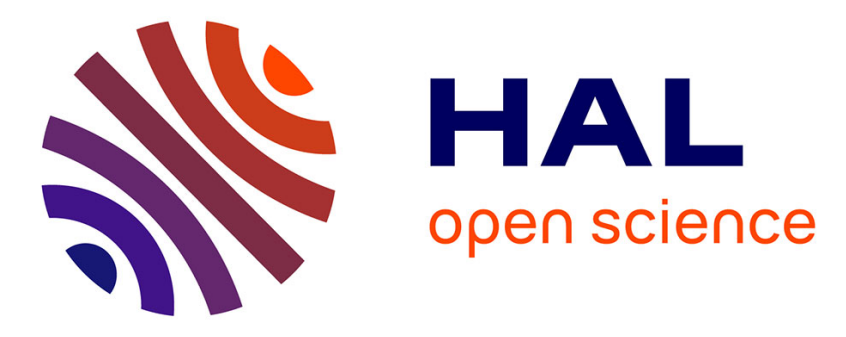

\title{
Short-Circuit Withstand Tests of 2605SA1-based Amorphous Distribution Transformers
}

Malick Mouhamad, Christophe Elleau, Frederic Mazaleyrat, Christian Guillaume, Bertrand Jarry

\section{- To cite this version:}

Malick Mouhamad, Christophe Elleau, Frederic Mazaleyrat, Christian Guillaume, Bertrand Jarry. Short-Circuit Withstand Tests of 2605SA1-based Amorphous Distribution Transformers. IEEE Transactions on Magnetics, 2011, 47 (10), pp.14489-4492. 10.1109/TMAG.2011.2155632 . hal-00661849

\section{HAL Id: hal-00661849 \\ https://hal.science/hal-00661849}

Submitted on 20 Jan 2012

HAL is a multi-disciplinary open access archive for the deposit and dissemination of scientific research documents, whether they are published or not. The documents may come from teaching and research institutions in France or abroad, or from public or private research centers.
L'archive ouverte pluridisciplinaire HAL, est destinée au dépôt et à la diffusion de documents scientifiques de niveau recherche, publiés ou non, émanant des établissements d'enseignement et de recherche français ou étrangers, des laboratoires publics ou privés. 


\title{
Short-Circuit Withstand Tests of 2605SA1-based Amorphous Distribution Transformers
}

\author{
Malick Mouhamad $^{1}$, Christophe Elleau ${ }^{1}$, Frédéric Mazaleyrat ${ }^{2}$, Christian Guillaume $^{1}$ and Bertrand Jarry ${ }^{3}$ \\ ${ }^{1}$ EDF R\&D, Laboratoire des Matériels Electriques, Moret sur Loing-77250, France \\ ${ }^{2}$ SATIE, ENS Cachan, CNRS, Universud, Cachan-94230, France \\ ${ }^{3}$ ERDF DFI, Tour Winterthur, Puteaux-92085, Paris La Défense, France
}

\begin{abstract}
This paper deals with EDF Research and Development work for ERDF needs in terms of energy efficiency, focused on Amorphous Metal Distribution Transformers (AMDT). Many prototypes built on METGLAS ${ }^{\circledR} 2605 S A 1$, rated 250 to $630 \mathrm{kVA}$ from different manufacturers, were tested under short-circuit conditions according to IEC and ERDF standards. Some of the prototypes exceeded the accepted value of $4 \%$ of impedance variation after short-circuit. Rectangular windings offer poor resistance to short-circuit stresses. Small metal particles, detached from amorphous core, were found at the bottom of the tank. In that case, dielectric strength is not gifted. The results show the active part should be strong enough to support high electrodynamic forces produced during short-circuit test.
\end{abstract}

Keywords - Amorphous transformers; Short-circuit withstand

\section{INTRODUCTION}

Reducing losses in the distribution networks has become a major objective that most of worldwide utilities are coping with today. Regarding the French MV networks, 1/3 of the technical losses are located in the MV/LV transformers whose $2 / 3$ of them correspond to their no-load losses [1]. In that purpose, the French DSO ERDF has decided to reduce the noload losses level of distribution transformers by studying the possible use of amorphous technology for transformer cores [3]. Although this latter technology is a well known energyefficient solution experienced since a long time at a large scale in many areas (mainly in the United States and Asia [2]), a few technical questions still need to be addressed to ensure amorphous transformers are completely suited to the French networks and their operational constraints.

It is known that the utility and industry require all different types and sizes of transformers ranging from small transformers (distribution sector $<1500 \mathrm{kVA}$ ) with a simple two winding arrangement, to a very large high voltage units with very complicated winding arrangements. A variety of cores and conductors is available ranging from core type and shell type construction, foil conductors, strip conductors.

Transformers are usually very reliable items of equipment, but when faults occur, they could be very expensive to repair. During operating conditions, transformers are submitted to a variety of electrical, mechanical and thermal stresses. One of the most critical situations is that caused by short-circuits, which produces high currents in the transformer windings and hence high internal forces in the windings. Transformers are specified and designed to withstand the effects of limited duration short-circuits at their terminals. Short-circuit faults are potentially very destructive since if the clamping system is not capable of restraining the forces involved, substantial permanent winding deformation or even collapse can occur almost instantaneously. A common cause of such failures is a close-up phase to earth fault resulting from a lightning strike.
It is expected that a transformer will be subjected to a number of short-circuits during its service life, but sooner or later one such event will cause some slight winding movement, and the ability of the transformer to resist further short-circuits will then be severely reduced. It is therefore desirable to be able to check the mechanical condition of transformers before to provide an early warning of an impeding failure.

Amorphous transformers is of no exception and they should be able to resist electrodynamic forces during short-circuit test. Short-circuit withstand is one the most important aspects which will approve this technology. This paper deals with the short-circuit tests carried out on amorphous prototypes. These investigations will verify if these AMDTs, intended for distribution network $(20 \mathrm{kV} / 0.410 \mathrm{kV})$, fulfill ERDF requirements.

\section{EXPERIMENTAL SETUP AND CALCULATIONS}

\section{A. Short-circuit test}

Transformers together with all equipment and accessories shall be designed and constructed to withstand without damage the thermal and dynamic effects of external shortcircuits.

In accordance with IEC 60076-5 standard and ERDF specification, the short-circuit withstand test is required for each power of transformer and the way it should be conducted is the following:

- $\quad$ Prior to the short-circuit tests, the transformer shall be subjected to the routine tests which are specified in IEC 60076-1.

- 9 short-circuits of $0,5 \mathrm{~s}$ duration each (3 on each column).

- All the routine tests, including dielectric tests should be repeated. A lightning impulse test shall be performed at this stage. 
- Inspection of the active part at the end of all the tests : no arcing or overheating marks, no deformation, no loosening and no displacement of any kind (connections, wedges, papers, press-boards, etc.), no particle or deposit in the dielectric liquid [4]

In order to consider the transformer as having passed the short-circuit test, the following conditions should be fulfilled:

- The results of the short-circuit tests and the measurements and checks performed during tests do not reveal any condition of faults.

- The dielectric tests and other routine tests when applicable, have been successfully repeated and the lightning impulse test, if specified, successfully performed.

- The out-of-tank inspection does not reveal any defects such as displacements, shift of laminations, deformation of windings, connections or supporting structures, so significant that they might endanger the safe operation of the transformer.

- No traces of internal electrical discharge are found.

- The short-circuit impedance values, in ohms, evaluated for each phase at the end of the tests, do not differ from the original values by more than $4 \%$ [5].

\section{B. Calculations}

\section{1) Short-circuit current $I_{S C}$}

The calculations are given for a $400 \mathrm{kVA}$-rated $\mathrm{HV} / \mathrm{LV}$ transformer. Before calculating the electrodynamic force in the windings, the short-circuit current level should be evaluated. Consider a short-circuit case as reported in Fig. 1 where all the phases are in contact. $\mathrm{Z}_{\mathrm{TR}}, \mathrm{X}_{\mathrm{TR}}$ and $\mathrm{R}_{\mathrm{TR}}$ represent transformer short-circuit impedance, reactance and resistance in a three-phase model. Their expressions are:

$$
\begin{gathered}
Z_{T R}=\frac{U_{c c}}{100} \times \frac{U}{\sqrt{3} \times I_{n}} \\
R_{T R}=\frac{P_{k}}{3 \times I_{n}^{2}} \\
X_{T R}=\sqrt{Z_{T R}^{2}-R_{T R}^{2}}
\end{gathered}
$$

$\mathrm{U}_{\mathrm{cc}}$ : transformer short-circuit voltage (4\%)

$\mathrm{U}$ : rated voltage of the winding $(410 \mathrm{~V})$

$\mathrm{I}_{\mathrm{n}}$ : nominal current $(563 \mathrm{~A})$

$\mathrm{P}_{\mathrm{k}}$ : load losses $\left(4600 \mathrm{~W}, \mathrm{C}_{\mathrm{k}}\right.$ level $)$

The equation to determine the short-circuit current level $\mathrm{I}_{\mathrm{SC}}$ is given by expression (4).

$$
I_{S C}=\frac{U}{\sqrt{3} \times\left(Z_{T R}+Z_{S}\right)}
$$

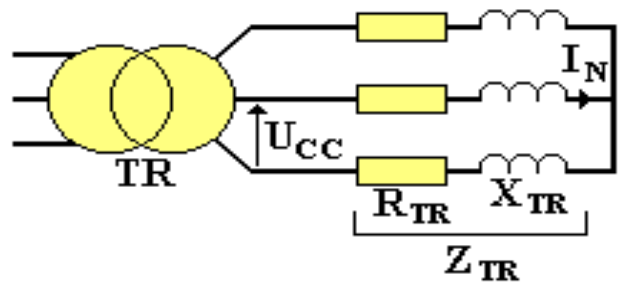

Fig. 1. Three-phase short-circuit default.

$Z_{S}$ is the sort-circuit impedance of the system. In order to simplify, we consider $Z_{\mathrm{S}} \approx 0$.

In a $400 \mathrm{kVA}$-rated $\mathrm{HV} / \mathrm{LV}$ transformer, $\mathrm{I}_{\mathrm{SC}}$ reaches $14.1 \mathrm{kA}$. This value should not be neglected as the electrodynamic force depends mainly on it.

\section{2) Electrodynamic force}

The electrodynamic forces in transformer windings are generated by the interaction between current density and flux density. In a transformer with concentric windings, there is a mutual axial repulsion between the inner and outer windings as shown in the Fig. 2. With the transformer operating under normal conditions, the forces are small. However, during short-circuit situations, the currents and fluxes reach high values, producing extreme electrodynamic forces. As the flux can be expressed as a function of the current, the resultant force will be proportional to the squared current.

According to Ampere's law, the force between two current-carrying parallel conductors is given in (5):

$$
F=\frac{\mu_{0}}{2 \pi} \frac{N_{1} I_{1} \times N_{2} I_{2}}{d}=\frac{\mu_{0}}{2 \pi} \frac{\left(N_{2} I_{2}\right)^{2}}{d}
$$

F : electrodynamic force during short-circuit $\left(\mathrm{N} . \mathrm{m}^{-1}\right)$

$\mu_{0}$ : vacuum permeability $\left(=4 \pi \cdot 10^{-7} \mathrm{H} \cdot \mathrm{m}^{-1}\right)$

$\mathrm{N}_{1}, \mathrm{~N}_{2}$ : number of turns in $\mathrm{HV}$ and $\mathrm{LV}$ windings

$\mathrm{I}_{1}, \mathrm{I}_{2}$ : current across HV and LV (A)

$\mathrm{d}$ : distance separating the windings $(\mathrm{m})$

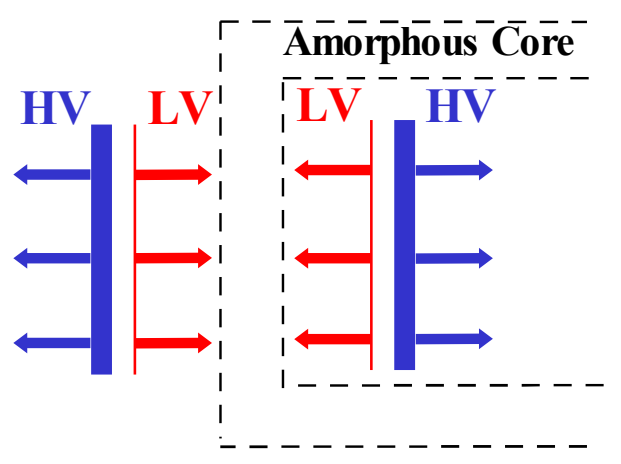

Fig. 2. Axial repulsion between High and Low voltage windings. 
During short-circuit default, the current reaches $14.1 \mathrm{kA}$ as previously calculated. The insulation distance between $\mathrm{HV}$ and $\mathrm{LV}$ is $7.5 .10^{-3} \mathrm{~m}$. The number of turns in $\mathrm{LV}$ winding is 21. These values were taken from a typical $400 \mathrm{kVA}$ amorphous distribution transformer.

By applying blindly the equation (5), a value of $4000 \mathrm{kN} \cdot \mathrm{m}^{-1}$ as resulting force during short-circuit is found. This value is very excessive considering the transformer mechanical ability. At this rate, a sudden mechanical break down of any transformer is imminent during short-circuit test. So the Ampere's force law should be carefully used in order to calculate the electrodynamic force. To estimate correctly this force, windings picturization is needed. Fig. 3 represents a zoom of parallel HV and LV conductors.

It is observed each winding has a thickness $\mathbf{e}$ with isolation distance $\mathbf{d}$ between them. Ampere's law takes into account only the distance $\mathbf{d}$ but the thickness should also be considered. For example, the electrodynamic forces generated by LV winding on HV are not the same in position $\mathbf{1}$ and position $\mathbf{2}$ as the distance $\mathbf{e}$ is higher than $\mathbf{d}$. To calculate the electrodynamic forces between the windings, the formula (5) should be integrated taking into account $\mathbf{d}$ and $\mathbf{e}$ :

Let $\mathrm{x}$ such as : $\mathrm{d}+\mathrm{e}<\mathrm{x}<2 \mathrm{e}+\mathrm{d}$

$$
\begin{aligned}
& d F(x)=\frac{\|_{0}}{2 \pi} N_{1} I_{1} \cdot \frac{d I_{2}}{x}=\frac{\|_{0}}{2 \pi} N_{1} I_{1} \cdot \frac{N_{2} I_{2}}{e} \frac{d x}{x}=\frac{\sharp_{0}}{2 \pi} \frac{\left(N_{2} I_{2}\right)^{2}}{e} \cdot \sqrt{3} \cdot \frac{d x}{x}
\end{aligned}
$$

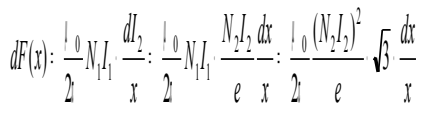

$$
\begin{aligned}
& F=K \int_{d+e}^{2 e+d} \frac{d x}{x}=K \cdot[\ln x]_{d+e}^{2 e+d}=K \cdot \ln \frac{d+2 e}{d+e} \\
& \text { Where } K=\frac{\mu_{0}}{2 \pi} \frac{\left(N_{2} I_{2}\right)^{2}}{e} \cdot \sqrt{3}
\end{aligned}
$$

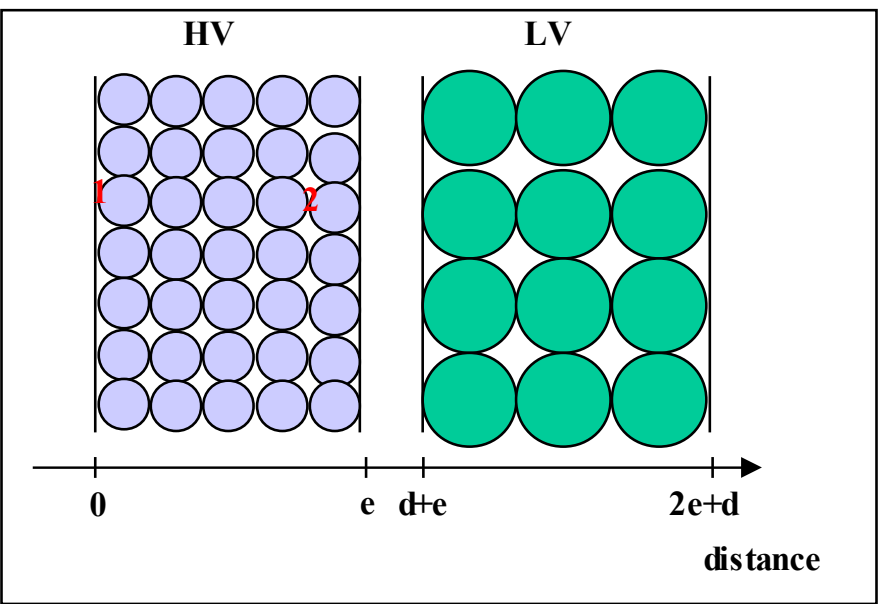

Fig. 3. Drawing of HV and LV conductors. Round shape objects represent the wires in the windings.

Input data:

$\mathrm{I}_{\mathrm{SC} 2}(\mathrm{LV})=14.1 \mathrm{kA}$

$\mathrm{N}_{2}=21$ spires

$\mathrm{d}=7.5 \cdot 10^{-3} \mathrm{~m}$ and $\mathrm{e}=5.10^{-2} \mathrm{~m}$

$\mu_{0}=4 \pi \cdot 10^{-7} \mathrm{H} \cdot \mathrm{m}^{-1}$

Calculations:

$\mathrm{K} \approx 600000$ and $\ln \frac{d+2 e}{d+e}=\ln \frac{0.1+0.0075}{0.05+0.0075} \approx 0.63$

$\mathrm{F}=0.63 \times 6.10^{5}=378 \mathrm{kN} \cdot \mathrm{m}^{-1}$

The calculated electrodynamic forces value is acceptable than the previous one $\left(4000 \mathrm{kN} \cdot \mathrm{m}^{-1}\right)$. Transformer manufacturers should take into account these forces in order to build the active part. For amorphous cores, great caution should be given to reinforce the active part because the windings are rectangular (Fig. 4), rather circular. So, short-circuit test will expose the know-how of each manufacturer.

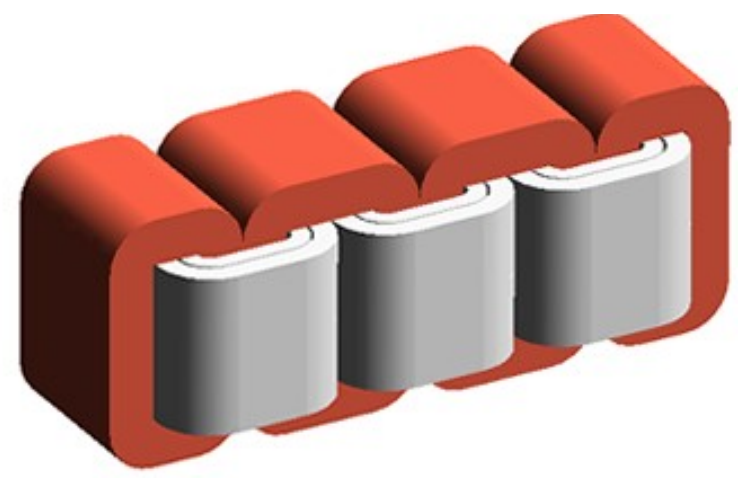

Fig. 4. Active part of a 3-phase amorphous transformer consisting of 4 magnetic cores and 3 rectangular windings.

\section{RESULTS AND DISCUSSIONS}

Transformers are regularly sampled and subjected to several routine tests including short-circuit test (SC) in order to guarantee the quality of the devices. In France, three-phase SC test consists of 3 impulses on each phase which account for 9 impulses in total. After each impulse, impedance variation (in $\%)$ is measured. This value plays a crucial part in certifying transformers in general. It should be mentioned that after SC, several tests will be conducted in order to analyze dielectric and magnetic properties of the transformer.

The prototypes received from different manufacturers were all made from SA1-based amorphous cores. The SC tests were carried out at EDF R\&D. The impedance variation after SC are given below in Tab.1. It is observed the impedance values defer from one manufacturer to another, independently of transformer power. According to ERDF requirements, out of 8 prototypes received, 4 are cleared after SC tests. As previously mentioned, the shape of the windings in amorphous products is rectangular. In that configuration, electrodynamic stresses 
are not uniformly distributed, unlike conventional circular coils. In Fig. 5, a drawing of a rectangular winding before and after SC is presented, which shows an important deformation of the coil due to its irregular shape. LV winding adopts a flattened profile and the HV tends to take a circular design where stress is equally shared.

Both amorphous transformers from M3 passed the SC test but failed in partial discharge measurement. In fact, dielectric withstand before and after SC is absolutely needed to ensure a smooth running of the transformer in the distribution network. At last, only 2 (400 kVA from M2 and $250 \mathrm{kVA}$ from M2) out of 8 devices are accepted.

After SC tests, prototypes were opened up for a deeper inspection of their active parts. During examination of some of them, small particles of amorphous ribbons were discovered at the bottom of the tank. These metal pieces are counterproductive during partial discharge measurement, as it was found in M2 transformers.

In fact, during SC, extreme electrodynamic forces cause the windings to deform and this shape deformity creates a lot of shear stress on amorphous cores which lead to breakup of some ribbons. The active part of an amorphous transformer should be strong enough to counterattack these stresses.

TABLE I

RESULTS FROM SHORT-CIRCUIT TESTS ON AMORPHOUS PROTOTYPES.

\begin{tabular}{|l|l|c|c|c|}
\hline Manufacturer & Year & $\begin{array}{c}\text { Rated Power } \\
\text { (kVA) }\end{array}$ & $\begin{array}{c}\text { Max. } \\
\text { Deviation } \\
\text { over 3 ph. }\end{array}$ & $\begin{array}{c}\text { Results } \\
\text { after SC } \\
\text { test }\end{array}$ \\
\hline M1 - Tr1 & 1997 & 400 & $6,0 \%$ & NS \\
\hline M2 - Tr1 & 2008 & 400 & $0,5 \%$ & S \\
\hline M3 - Tr1 & 2009 & 400 & $1,4 \%$ & S \\
\hline M3 - Tr2 & 2009 & 630 & $3,0 \%$ & S \\
\hline M4 - Tr1 & 2010 & 250 & $1,6 \%$ & S \\
\hline M4 - Tr2 & 2010 & 400 & $6,5 \%$ & NS \\
\hline M5 - Tr1 & 2009 & 400 & $5,0 \%$ & NS \\
\hline M5 - Tr2 & 2010 & 400 & $5,9 \%$ & NS \\
\hline
\end{tabular}

Due to confidential reasons, the name of manufacturers are not disclosed. S : Satisfying NS : Not satisfying

Fig. 3. Drawing of a rectangular winding before and after SC test. The arrows represent the electrodynamic forces in HV and LV conductors.

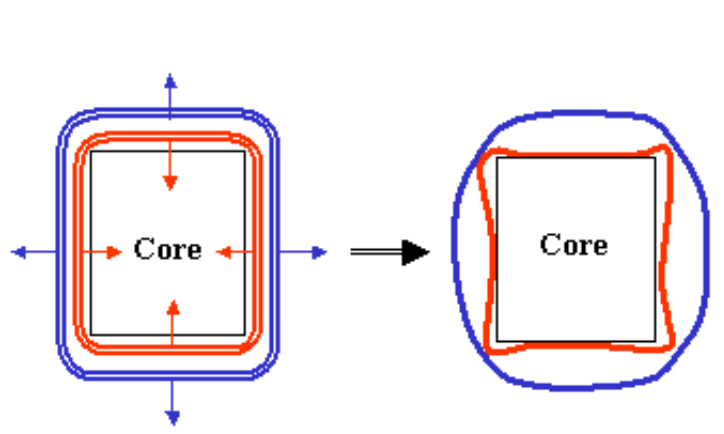

\section{CONCLUSION}

Manufacturers should conceive a well built design taking into account all possible damages during SC. This constitutes the major limitation of the specification and is the hardest for transformers built from amorphous ribbons. This is the reason why amorphous transformers are suitable for low-rated power and single-phase devices.

Although the performance of amorphous transformers, in terms of loss reduction, are a breakthrough, the design of the active part should be improved to cope with ERDF requirements.

\section{ACKNOWLEDGMENT}

\section{REFERENCES}

[1] R. Targosz, F. Topalis and W. Irrek, "Selecting energy-efficient distribution transformers: A guide for achieving least-cost solutions," SEEDT Project (2008)

[2] M. Sampat, "Amorphous metal transformer: Next steps," EPRI (2009), 1017898

[3] B. Jarry, P. Lauzevis, P. Lagache and Michel SACOTTE, "Amorphous sheet core transformers under experimentation on the ERDF network," CIRED (2009), Paper 0090

[4] IEC, "Power Transformers - Ability to withstand short-circuit," 60076 Part 5 (2006)

[5] EDF technical specification, "Three-phase, immersed, MV/LV distribution transformers, $50 \mathrm{~Hz}$, from 50 to $1000 \mathrm{kVA}$, with highest voltage for equipment not exceeding $24 \mathrm{kV}$," HN 52-S-27 (2008) 